\title{
The maternal origin of indigenous domestic chicken from the Middle East, the north and the horn of Africa
}

\author{
Ahmed S. Al-Jumaili, ${ }^{1 *}$ (D), Selma Farah Boudali ${ }^{3}$, Adebabay Kebede ${ }^{4,5}$, Sahar A. Al-Bayatti ${ }^{6}$, Abdulamir A. Essa ${ }^{6}$, \\ Abulgasim Ahbara ${ }^{1}$, Riyadh S. Aljumaah ${ }^{7}$, Raed M. Alatiyat ${ }^{8}$, Joram M. Mwacharo ${ }^{9}$, Gro Bjørnstad ${ }^{10}$, Arifa N. Naqvi ${ }^{11}$, \\ Semir Bechir Suheil Gaouar ${ }^{12}$ and Olivier Hanotte ${ }^{1,5^{*}}$
}

\begin{abstract}
Background: Indigenous domestic chicken represents a major source of protein for agricultural communities around the world. In the Middle East and Africa, they are adapted to hot dry and semi-dry areas, in contrast to their wild ancestor, the Red junglefowl, which lives in humid and sub-humid tropical areas. Indigenous populations are declining following increased demand for poultry meat and eggs, favouring the more productive exotic commercial breeds. In this paper, using the D-loop of mitochondrial DNA as a maternally inherited genetic marker, we address the question of the origin and dispersal routes of domestic chicken of the Middle East (Iraq and Saudi Arabia), the northern part of the African continent (Algeria and Libya) and the Horn of Africa (Ethiopia).

Results: The analysis of the mtDNA D-loop of 706 chicken samples from Iraq $(n=107)$, Saudi Arabia $(n=185)$, Algeria $(n=88)$, Libya $(n=23)$, Ethiopia $(n=211)$ and Pakistan $(n=92)$ show the presence of five haplogroups $(A, B$, C, D and E), suggesting more than one maternal origin for the studied populations. Haplogroup $E$, which occurred in 625 samples, was the most frequent in all countries. This haplogroup most likely originates from the Indian subcontinent and probably migrated following a terrestrial route to these different countries. Haplotypes belonging to haplogroup D were present in all countries except Algeria and Libya, it is likely a legacy of the Indian Ocean maritime trading network. Haplogroup A was present in all countries and may be of commercial origin. Haplogroup B was found only in Ethiopia. Haplogroup C was only detected in the South-Western region of Saudi Arabia and in Ethiopia.

Conclusion: The results support a major influence of the Indian subcontinent on the maternal diversity of the today's chicken populations examined here. Most of the diversity occurs within rather than between populations. This lack of phylogeographic signal agrees with both ancient and more recent trading networks having shaped the modern-day diversity of indigenous chicken across populations and countries.
\end{abstract}

Keywords: Domestic chicken, Dispersal routes, Genetic diversity, Middle East, Africa

\footnotetext{
* Correspondence: ahmedaljumiliy@gmail.com;

olivier.hanotte@nottingham.ac.uk; o.hanotte@cgiar.org

'School of Life Sciences, the University of Nottingham, University Park, Nottingham NG7 2RD, UK

Full list of author information is available at the end of the article
}

(c) The Author(s). 2020 Open Access This article is licensed under a Creative Commons Attribution 4.0 International License, which permits use, sharing, adaptation, distribution and reproduction in any medium or format, as long as you give appropriate credit to the original author(s) and the source, provide a link to the Creative Commons licence, and indicate if changes were made. The images or other third party material in this article are included in the article's Creative Commons licence, unless indicated otherwise in a credit line to the material. If material is not included in the article's Creative Commons licence and your intended use is not permitted by statutory regulation or exceeds the permitted use, you will need to obtain permission directly from the copyright holder. To view a copy of this licence, visit http://creativecommons.org/licenses/by/4.0/ The Creative Commons Public Domain Dedication waiver (http://creativecommons.org/publicdomain/zero/1.0/) applies to the data made available in this article, unless otherwise stated in a credit line to the data. 


\section{Background}

Undoubtedly, village chickens are a valuable genetic resource for the countries around the world due to their adaptation to the local environment, including their higher resistance against endemic diseases. They supply highquality protein and represent a major source of income to poor communities. Therefore, they contribute greatly to food security, poverty alleviation and management of natural resources [1]. The main production system of indigenous chicken is scavenging or semi-scavenging, which relies on a low level of inputs. This system makes up to $80 \%$ of the poultry stocks in the developing countries of Asia and Africa [2].

The Red junglefowl is the main ancestor of the domestic chicken [3]. Its natural habitat is the sub-humid and humid tropical areas in South and South-East Asia. In contrast to the wild ancestor, village chickens have adapted very effectively to a diversity of environments including the arid and semi-arid areas. They show extensive morphological diversity that may be connected to the adaptation to such hot and dry environments, including the naked-neck phenotype, small body size and frizzled plumage [4-6]. Recent genome studies have revealed candidate regions under positive selection which may be related to environmental adaptation in this species [7].

MtDNA analysis has been used intensively to unravel the history of domestic chickens [8]. Analysis of the mitochondrial DNA genome allows us to identify the wild ancestor(s) and the maternal lines that have contributed to a breed or population [9, 10]. Furthermore, such genetic marker can offer valuable information concerning the human-mediated dispersal of the species out of the domestication centres [10]. Finally, mtDNA characterisation of diversity may help the establishment of effective management practices and sustainable strategies for the conservation of diversity.

This study aims to unravel the history and diversity of indigenous chicken from the Middle East, Northern and the Horn of Africa. It includes chicken from (i) Pakistan, a putative ancient centre of origin for domestic chicken in the northern part of the Indian subcontinent [11], (ii) Iraq, with its ancient Mesopotamian civilizations in contact with those of the Indus Valley, (iii) Saudi Arabia on the route to the African continent, (iv) the Horn of Africa, represented here by Ethiopia, where the oldest osteological evidence of domestic chicken for Africa have been found, dated from pre-Aksumite time [12], and (v) Algeria and Libya, two countries bordering the Mediterranean Sea, which witnessed ancient Phoenician, Greek and Roman terrestrial and maritime trading networks between North Africa, the Near East and Europe [13]. A total of 706 mtDNA $D$-loop sequences and Asian haplotypes of reference from Liu et al. [14] was analysed.

\section{Results}

\section{D-loop haplotype variation and genetic diversity}

Eighty-eight haplotypes defined by 63 polymorphic sites were identified in the 706 sequences (Additional file 1: Fig. S1). Each haplotype was abbreviated with the letter $\mathrm{H}$ followed by a number e.g. H_1, H_2, H_3 etc. The most frequent haplotype (41\%) was H_3 (291 sequences out of 706). H_3 includes 92 (50\%), 60 (28\%), 58 (54\%), 55 (63\%), 14 (15\%), 12 (52\%) of Saudi, Ethiopian, Iraqi, Algerian, Pakistani and Libyan sequences respectively. The next commonest haplotypes were $\mathrm{H} \_23$ and $\mathrm{H} \_4$, 7.6 and $6 \%$ of all the sequences, respectively. At a country level, other common haplotypes included $\mathrm{H} \_23$ present only in Ethiopian samples $(n=54,26 \%)$ and ${ }_{-} \_4$ present only in Pakistani chicken $(n=43,47 \%)$.

The Central region of Iraq showed a highly significant $(P \leq 0.001)$ and significant $(P \leq 0.05)$ levels of genetic diversity compared to the other regions (North-East and South), with haplotype diversities of $0.725 \pm 0.053$ (Baghdad) and $0.712 \pm 0.105$ (Karbala), but $0.438 \pm 0.121$ for Misan in the South-East, and $0.182 \pm 0.144$ for Basra in the South (Table 1 and Additional file 1: Table S2a). The same is applicable for the nucleotide diversity, which shows a highly significant $(P \leq 0.001)$ and significant $(P \leq 0.05)$ level of diversity in the Central region of the country (Additional file 1: Table S2b).

For the Algerian populations, Adrar, Oran and Tlemcen show higher haplotypes $(0.654 \pm 0.085,0.706 \pm$ 0.106 and $0.797 \pm 0.088)$ and nucleotides diversities $(0.0035 \pm 0.0006,0.0022 \pm 0.0005$ and $0.00565 \pm 0.0021)$ compared to the haplotypes $(0.363 \pm 0.131$ and $0.182 \pm$ $0.144)$ and nucleotides $(0.001 \pm 0.0004$ and $0.0009 \pm$ $0.0007)$ diversities for Mascara and Tiaret, respectively. Significant $(P \leq 0.05)$ haplotypes diversity differences found between Tlemcen and Tiaret, Tlemcen and Mascara, Adrar and Tiaret and Oran and Tiaret (Additional file 1: Table S3a) populations. On the other side, only two significant differences $(P \leq 0.001$ and $P \leq 0.05)$ for nucleotide variation between Mascara and Tlemcen on the first level, and between Tiaret and Tlemcen on the second level (Additional file 1: Table S3b) are observed.

In Ethiopia, different populations show different levels of diversity, with a highly significant $(P \leq 0.001)$ and significant $(P \leq 0.05)$ haplotypes diversities for Adane, Arabo, Kumato, Loya, Meseret and Shubi (Additional file 1: Table S4a), and with the nucleotide diversities for the same populations ranging between $0.0033-0.0145$, with a highly significant $(P \leq 0.001)$ or significant $(P \leq 0.05)$ differences among populations (Additional file 1: Table $\mathrm{S} 4 \mathrm{~b}$ ). At a regional level, the North, Central-East and West regions do not show significant differences in their diversities, but the South region has the highest level of genetic variation compared to the other regions. 
Table 1 Location, sample size and genetic diversity of the samples included in this study

\begin{tabular}{|c|c|c|c|c|c|c|}
\hline Country/population & $\mathrm{N}$ & $S$ & $\mathrm{H}$ & $\mathrm{Hd}(\mathrm{SD})$ & $\pi(S D)$ & $\mathrm{K}$ \\
\hline \multicolumn{7}{|l|}{$\begin{array}{l}\text { Iraqi populations } \\
\text { North-East }\end{array}$} \\
\hline Sulimania [1] & 9 & 0 & 1 & $0(0)$ & $0(0)$ & 0 \\
\hline \multicolumn{7}{|l|}{ Central } \\
\hline Baghdad & 51 & 18 & 12 & $0.725(0.053)$ & 0.0080 (0.0009) & 3.167 \\
\hline Karbala & 12 & 5 & 4 & $0.712(0.105)$ & $0.0043(0.0010)$ & 1.697 \\
\hline Central [2] & 63 & 20 & 14 & $0.736(0.051)$ & $0.0075(0.0008)$ & 2.988 \\
\hline \multicolumn{7}{|l|}{ South } \\
\hline Basra & 11 & 1 & 2 & $0.182(0.144)$ & 0.0005 (0.0003) & 0.182 \\
\hline Misan & 24 & 11 & 5 & $0.438(0.121)$ & $0.0034(0.0015)$ & 1.359 \\
\hline South [3] & 35 & 12 & 6 & $0.361(0.103)$ & $0.0025(0.0011)$ & 1.002 \\
\hline Total & 107 & 22 & 18 & $0.686(0.047)$ & $0.0067(0.0007)$ & 2.652 \\
\hline \multicolumn{7}{|c|}{$\begin{array}{l}\text { Algerian populations } \\
\text { North-West }\end{array}$} \\
\hline Mascara & 20 & 3 & 4 & $0.363(0.131)$ & $0.0010(0.0004)$ & 0.389 \\
\hline Oran & 17 & 5 & 6 & $0.706(0.106)$ & $0.0022(0.0005)$ & 0.882 \\
\hline Tiaret & 11 & 2 & 2 & $0.182(0.144)$ & $0.0009(0.0007)$ & 0.364 \\
\hline Tlemcen & 18 & 15 & 8 & 0.797 (0.088) & $0.0056(0.0021)$ & 2.242 \\
\hline North-West [1] & 66 & 19 & 12 & $0.569(0.072)$ & $0.0025(0.0007)$ & 1.030 \\
\hline \multicolumn{7}{|l|}{ Central } \\
\hline Adrar [2] & 22 & 5 & 4 & $0.654(0.085)$ & $0.0035(0.0006)$ & 1.403 \\
\hline Total & 88 & 20 & 13 & $0.597(0.060)$ & $0.0028(0.0006)$ & 1.145 \\
\hline \multicolumn{7}{|c|}{$\begin{array}{l}\text { Ethiopian populations } \\
\text { North }\end{array}$} \\
\hline Mihquan & 10 & 9 & 3 & $0.644(0.101)$ & $0.0054(0.0031)$ & 2.156 \\
\hline Meseret & 10 & 11 & 6 & $0.867(0.085)$ & $0.0072(0.0026)$ & 2.844 \\
\hline North [1] & 20 & 14 & 7 & $0.742(0.071)$ & $0.0061(0.0021)$ & 2.447 \\
\hline \multicolumn{7}{|l|}{ Central-East } \\
\hline Adane & 10 & 11 & 5 & $0.800(0.100)$ & $0.0082(0.0029)$ & 3.244 \\
\hline Arabo & 10 & 4 & 5 & $0.844(0.080)$ & $0.0033(0.0006)$ & 1.289 \\
\hline Horro & 30 & 10 & 5 & $0.644(0.081)$ & $0.0068(0.0017)$ & 2.699 \\
\hline Jarso & 14 & 0 & 1 & $0(0)$ & $0(0)$ & 0 \\
\hline Midir & 10 & 2 & 3 & $0.600(0.131)$ & $0.0017(0.0005)$ & 0.667 \\
\hline Negasi_Amba & 10 & 1 & 2 & 0.467 (0.132) & $0.0012(0.0003)$ & 0.467 \\
\hline Central-East [2] & 84 & 20 & 10 & $0.774(0.027)$ & $0.0092(0.0010)$ & 3.674 \\
\hline \multicolumn{7}{|l|}{ West } \\
\hline Ashuda & 10 & 1 & 2 & 0.356 (0.159) & $0.0009(0.0004)$ & 0.356 \\
\hline Amshi & 10 & 1 & 2 & $0.533(0.095)$ & $0.0013(0.0002)$ & 0.533 \\
\hline Batambie & 8 & 1 & 2 & $0.250(0.180)$ & $0.0006(0.0004)$ & 0.250 \\
\hline Dikuli & 10 & 2 & 3 & $0.600(0.131)$ & $0.0017(0.0005)$ & 0.667 \\
\hline Gafera & 10 & 1 & 2 & 0.467 (0.132) & $0.0012(0.0003)$ & 0.467 \\
\hline Surta & 9 & 1 & 2 & $0.222(0.166)$ & $0.0006(0.0004)$ & 0.222 \\
\hline Tzion_Teguaz & 10 & 3 & 3 & $0.600(0.131)$ & $0.0024(0.0009)$ & 0.933 \\
\hline West [3] & 67 & 5 & 8 & 0.707 (0.044) & $0.0025(0.0002)$ & 1.000 \\
\hline
\end{tabular}


Table 1 Location, sample size and genetic diversity of the samples included in this study (Continued)

\begin{tabular}{|c|c|c|c|c|c|c|}
\hline Country/population & $\mathrm{N}$ & $\mathrm{S}$ & $\mathrm{H}$ & $\mathrm{Hd}(\mathrm{SD})$ & $\pi(S D)$ & K \\
\hline \multicolumn{7}{|l|}{ South } \\
\hline Girissa & 10 & 4 & 5 & $0.667(0.163)$ & $0.0027(0.0008)$ & 1.067 \\
\hline Kumato & 10 & 10 & 5 & $0.756(0.130)$ & $0.0082(0.0030)$ & 3.244 \\
\hline Loya & 10 & 8 & 5 & $0.756(0.130)$ & $0.0089(0.0020)$ & 3.533 \\
\hline Shubi_Gemo & 10 & 14 & 6 & $0.911(0.062)$ & $0.0145(0.0020)$ & 5.756 \\
\hline South [4] & 40 & 23 & 19 & $0.929(0.021)$ & $0.0150(0.0006)$ & 5.964 \\
\hline Total & 211 & 33 & 36 & $0.840(0.016)$ & $0.0094(0.0007)$ & 3.732 \\
\hline \multicolumn{7}{|l|}{ Saudi Arabia } \\
\hline East [1] & 45 & 18 & 15 & $0.856(0.044)$ & $0.0042(0.0008)$ & 1.697 \\
\hline Central [2] & 43 & 20 & 11 & $0.631(0.084)$ & $0.0037(0.0010)$ & 1.499 \\
\hline West [3] & 97 & 23 & 16 & $0.702(0.041)$ & $0.0041(0.0006)$ & 1.658 \\
\hline Total & 185 & 34 & 26 & $0.727(0.033)$ & $0.0041(0.0005)$ & 1.633 \\
\hline \multicolumn{7}{|l|}{ Other populations } \\
\hline Libya & 23 & 14 & 10 & 0.731 (0.099) & $0.0054(0.0018)$ & 2.142 \\
\hline Pakistan & 92 & 24 & 19 & $0.756(0.043)$ & $0.0088(0.001)$ & 3.503 \\
\hline \multicolumn{7}{|l|}{ Total } \\
\hline All the samples included in this study & 706 & 55 & 88 & $0.815(0.014)$ & $0.0077(0.0004)$ & 3.058 \\
\hline
\end{tabular}

$\mathrm{N}=$ number of samples, $\mathrm{S}=$ segregating sites, $\mathrm{H}=$ Number of haplotypes, $\mathrm{Hd}(\mathrm{SD})=$ haplotype diversity (standard deviation), $\pi(\mathrm{SD})=$ nucleotide diversity (standard deviation) and $\mathrm{K}=$ average number of nucleotide differences

The Saudi Arabian regions also show different significant levels of diversity (Additional file 1: S5a), with the highest haplotype diversity in the East on the shores of the Arabian Gulf $(0.856 \pm 0.044)$, then the West on the shores of the Red Sea $(0.702 \pm 0.041)$, while the lowest was in the Central region $(0.631 \pm 0.084)$. No significant differences are observed in Saudi Arabia for the nucleotide variation (Additional file 1: Table S5b). Libya and Pakistan show high diversity levels for both haplotype $(0.731 \pm 0.099$ and $0.756 \pm 0.043$ respectively) and nucleotide diversity $(0.0054 \pm 0.0018$ and $0.0088 \pm 0.001$, respectively).

At the country level, the highest haplotype diversity was present in Ethiopia and the lowest in Algeria. An intermediate level of haplotype variation was observed in Iraq, Libya, Pakistan and Saudi Arabia.

\section{Phylogeographic analysis}

Reference haplotypes from Liu et al. [14] were used to name the haplogroups accordingly to their nomenclatures (a, B, C, D, E, F, G, H and I). A maximum likelihood tree for the 88 haplotypes was constructed to assess the genetic relationships among them (Fig. 1). Most branches included show high confidence (bootstrap) relationship values ranging between 70 and 100, and suggest the presence of five haplogroups (a, B, C, $D$, and E). The haplotypes were classified in different haplogroups following the results of the tree and network for all the countries together, and an individual network for each country separately (Figs. 1, 2, Additional file 1: Fig. S2, Additional file 1: Fig. S3, Additional file 1: Fig. S4, Additional file 1: Fig. S5, Additional file 1: Fig. S6 and Additional file 1: Fig. S7). The frequency of each haplogroup in each country is indicated in Table 2. Haplogroup E is the most frequent one (625 individuals out of 706) followed by $\mathrm{D}$ $(n=46)$, a $(n=31), C(n=3)$ and B $(n=1)$. Haplogroup a is represented by 7 haplotypes, $\mathrm{B}$ by one, $\mathrm{C}$ by two and haplogroup D by 11 haplotypes

Haplogroup E is represented by different numbers of individuals and proportions in the six countries. It is present in 87 (99\%), 169 (80\%), 84 (79\%), 21 (91\%), 84 (91\%) and 180 (97\%) birds out of 625 for Algeria, Ethiopia, Iraq, Libya, Pakistan and Saudi Arabia, respectively. Haplogroup A is found in 31 samples (all countries). Haplogroup B and C were only found in Ethiopia and Saudi Arabia. One haplotype from Ethiopia was identical to the reference haplotype $B$, while $C$ was identified as one Ethiopian haplotype and one Saudi haplotype (represented by two samples from the South-West region). Haplotypes belonging to haplogroup D were present in all countries except Algeria and Libya. This haplogroup was represented by eleven haplotypes beside the reference one. It includes 34 (16\%), 8 (7\%), 3 (7\%) and $1(0.5 \%)$ samples, out of 46, for Ethiopia, Iraq, Pakistan and Saudi Arabia respectively. 


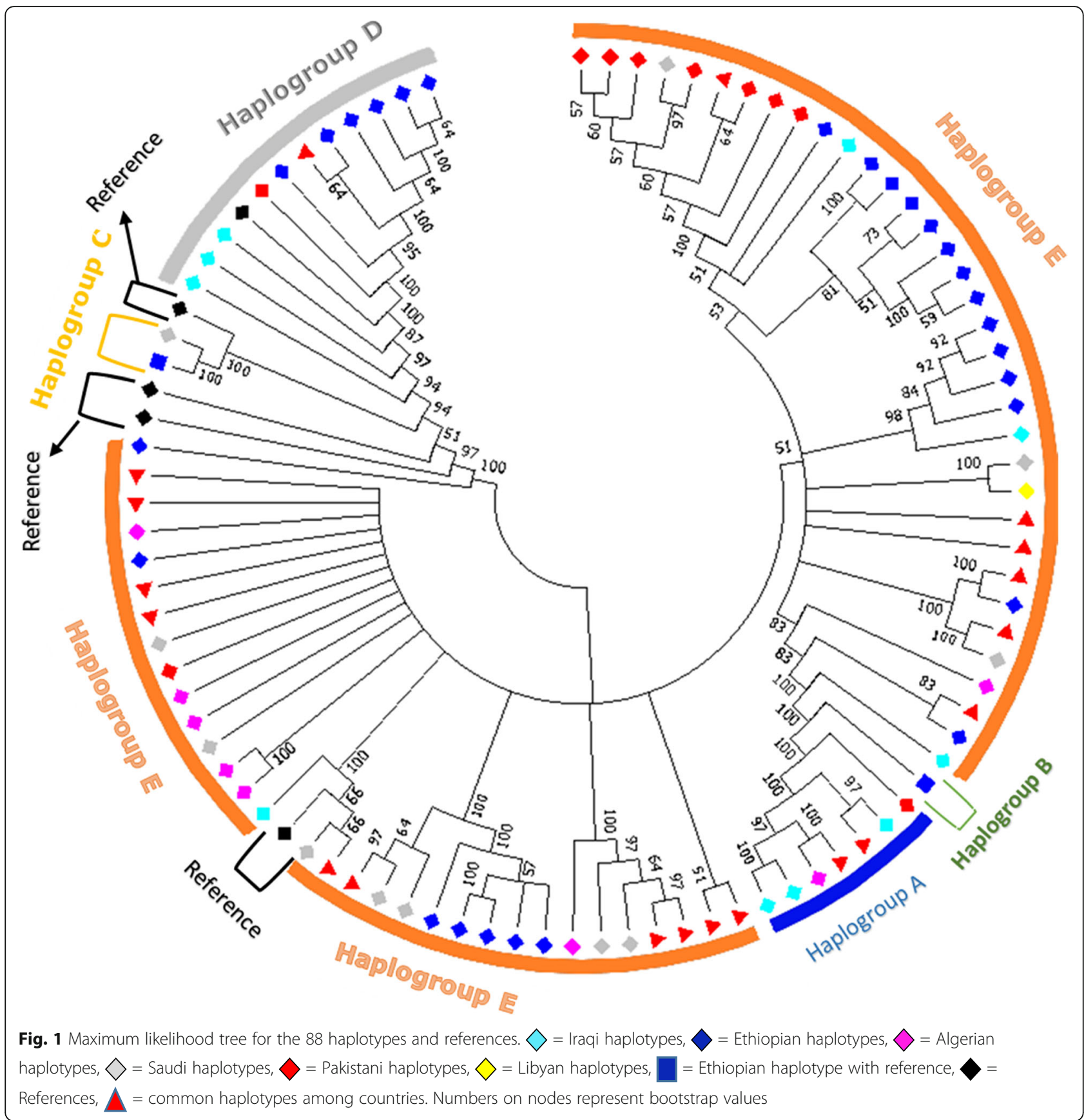

Network analysis allows further visualisation of the diversity of the haplotypes and their relationships. The most frequent haplotypes ( $\mathrm{H} \_3, \mathrm{H} \_4$ and $\mathrm{H} \_23$ ), belong to haplogroup E (Fig. 2). The first (H_3) is identical to the haplotype reference, $\mathrm{H}_{-} 4$ is different from the previous one by 4 mutations only, while only a single mutation separates $\mathrm{H} \_23$ from $\mathrm{H} \_3$. The links between haplogroup E and the other haplogroups are well resolved. Haplogroup $\mathrm{E}$ is separated from haplogroup $\mathrm{D}$ by several mutations with three median vectors (mv), while $C$ is connected to $E$ by 12 mutations and $5 \mathrm{mv}$. The same situation is applicable to other clusters except for haplogroup $\mathrm{F}$ which was connected to E by 7 mutations without median vectors. The presence of median vectors could be attributed to un-sampled haplotypes, e.g. haplotypes that have not been introduced to the geographical area or haplotypes that became extinct [15]. Haplotype H_3 (haplogroup E) at the centre of a star-like pattern is likely the ancestral haplotype for this haplogroup.

Both phylogenetic tree and network (Additional file 1: Fig. S8 \& S9) for the downloaded sequences showed similar results compared to phylogenies of the collected 


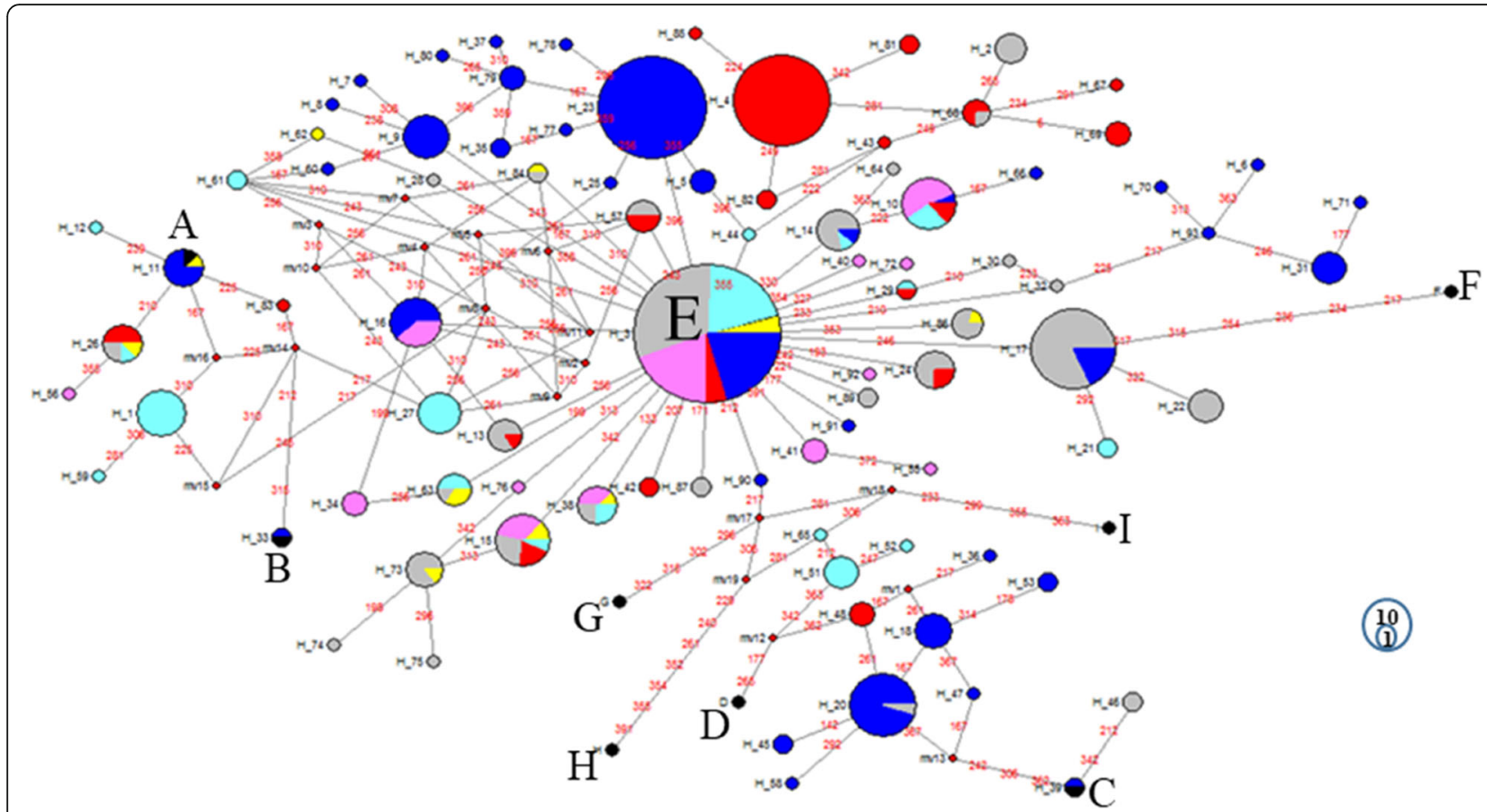

Fig. 2 Median-Joining network for Algeria, Ethiopia, Iraq, Libya, Pakistan and Saudi Arabia haplotypes. The black circles refer to the reference haplotypes. Pink = Algerian haplotypes, Blue $=$ Ethiopian haplotypes, Cyan = Iraqi haplotypes, Yellow $=$ Libyan haplotypes, Red = Pakistani haplotypes and Grey = Saudi Arabian haplotypes. The numbers on the branch indicate the position of the mutations, the circles are proportional to the numbers of haplotypes

samples. These results include the same haplogroups (A, B, C, D and E), and similar pattern of haplotypes distribution.

\section{Analysis of molecular variance (AMOVA)}

Both maternal genetic differentiation within and among populations were assessed for the samples included in this study (Table 3). The data were examined at three levels, among groups (regions within country) of populations, among populations within groups and among individuals within populations. The results show that the highest percentage of variation for Iraq and Algeria is found among individuals, 66.33 and $94.41 \%$ respectively, within populations. The percentage of differentiation among groups of Iraqi populations is higher than the one observed in Algeria, 28.89 and 5.03\% respectively. In Ethiopia, the percentage of variation for both populations within groups (45.84\%) and among individuals within populations (42.87\%) are relatively large, with lower variation among groups (11.29\%). The three regions of Saudi Arabia show most of the variation (96.66\%) among individuals within regions, and hardly any genetic differentiation among regions (3.34\%). In general, when we compare all the countries (Algeria, Ethiopia, Iraq, Libya, Pakistan and Saudi Arabia), the highest variation is found among individuals within populations (74.12\%), then among populations within countries (17.01\%).
Population history and demographic dynamics

The demographic pattern for each population and each country was examined. The Mean Absolute Error (MAE) values were moderate to low (Table 4). Results show negative non-significant Tajima's D values for many populations. The exceptions are Misan, Mascara, Tiaret, Tlemcen, North-West Algeria, South Iraq region, Libya and the East, Central and West regions of Saudi Arabia, where we observed negative and significant Tajima's D values. A negative Tajima's D signifies an excess of low-frequency polymorphisms relative to expectation, indicating population size expansion (following a bottleneck or a selective sweep) or purifying selection. Fu's Fs, also an index of population expansion, is known to be a more powerful tool than Tajima's D [40]. Its power comes from the ability to differentiate between population growth and genetic hitchhiking, and in rejecting the hypothesis of neutral mutations. No significance values were found for the Harpending raggedness index ( $r$ ) except for the Algerian samples, when they were grouped together. These results of MAE, Tajima's D, Fu's Fs and raggedness index (r) suggest a complex demographic history for our populations. We also performed mismatch distribution and Bayesian Skyline plot (BSP) analyses to gather more information regarding possible past population expansion.

The mismatch distribution graphs show three patterns: uni-, bi- and multi-modal (Fig. 3 and Additional file 1: Fig. 
Table 2 Distribution of haplotypes across haplogroups and countries

\begin{tabular}{|c|c|c|c|c|c|c|}
\hline Haplogroup/Haplotypes & Algeria & Ethiopia & Iraq & Libya & Pakistan & Saudi Arabia \\
\hline \multicolumn{7}{|l|}{ Haplogroup A } \\
\hline$H_{-} 1$ & & & 12 & & & \\
\hline H_11 & & 6 & & 1 & & \\
\hline H_12 & & & 1 & & & \\
\hline H_26 & & & 1 & 1 & 4 & 2 \\
\hline H_56 & 1 & & & & & \\
\hline H_59 & & & 1 & & & \\
\hline H_83 & & & & & 1 & \\
\hline
\end{tabular}

Table 2 Distribution of haplotypes across haplogroups and countries (Continued)

\begin{tabular}{|c|c|c|c|c|c|c|}
\hline Haplogroup/Haplotypes & Algeria & Ethiopia & Iraq & Libya & Pakistan & Saudi Arabia \\
\hline H_29 & & & 1 & & 1 & \\
\hline H_30 & & & & & & 1 \\
\hline H_31 & & 6 & & & & \\
\hline H_32 & & & & & & 1 \\
\hline H_34 & 3 & & & & & \\
\hline H_35 & & 2 & & & & \\
\hline H_36 & & & & & & \\
\hline H_37 & & 1 & & & & \\
\hline H_38 & 3 & & 2 & 1 & & 2 \\
\hline H_40 & 1 & & & & & \\
\hline H_41 & 3 & & & & & \\
\hline H_42 & & & & & 2 & \\
\hline H_43 & & & & & 1 & \\
\hline H_44 & & & 1 & & & \\
\hline H_55 & 1 & & & & & \\
\hline H_57 & & & & & 3 & 3 \\
\hline H_60 & & 1 & & & & \\
\hline H_61 & & & 2 & & & \\
\hline H_62 & & & & 1 & & \\
\hline H_63 & & & 3 & 2 & & 1 \\
\hline H_64 & & & & & & 1 \\
\hline H_66 & & 1 & & & & \\
\hline H_67 & & & & & 1 & \\
\hline H_68 & & & & & 3 & 1 \\
\hline H_69 & & & & & 3 & \\
\hline H_70 & & 1 & & & & \\
\hline H_71 & & 1 & & & & \\
\hline H_72 & 1 & & & & & \\
\hline H_73 & & & & 1 & & 6 \\
\hline H_74 & & & & & & 1 \\
\hline H_75 & & & & & & 1 \\
\hline H_76 & 1 & & & & & \\
\hline H_77 & & 1 & & & & \\
\hline H_78 & & 1 & & & & \\
\hline H_79 & & 3 & & & & \\
\hline H_80 & & 1 & & & & \\
\hline H_81 & & & & & 2 & \\
\hline H_82 & & & & & 2 & \\
\hline H_84 & & & & 1 & & 1 \\
\hline H_85 & & & & & 1 & \\
\hline H_86 & & & & 1 & & 4 \\
\hline H_87 & & & & & & 2 \\
\hline H_89 & & & & & & 2 \\
\hline H_90 & & 1 & & & & \\
\hline H_91 & & 1 & & & & \\
\hline H_92 & 1 & & & & & \\
\hline H_93 & & 1 & & & & \\
\hline
\end{tabular}


Table 3 Analysis of Molecular Variance (AMOVA)

\begin{tabular}{|c|c|c|c|c|}
\hline Grouping & Source of variation & Degrees of freedom & Variance components & Percentage of variation \\
\hline \multirow[t]{4}{*}{ Iraq } & Among groups & 2 & $0.44860 \mathrm{Va}$ & 28.89 \\
\hline & Populations within groups & 2 & $0.07417 \mathrm{Vb}$ & 4.78 \\
\hline & Within populations & 102 & $1.02984 \mathrm{VC}$ & 66.33 \\
\hline & Total & 106 & 1.55261 & \\
\hline \multirow[t]{4}{*}{ Algeria } & Among groups & 1 & $0.02977 \mathrm{Va}$ & 5.03 \\
\hline & Populations within groups & 3 & $0.00331 \mathrm{Vb}$ & 0.56 \\
\hline & Within populations & 83 & $0.55855 \mathrm{Vc}$ & 94.41 \\
\hline & Total & 87 & 0.59163 & \\
\hline \multirow[t]{4}{*}{ Ethiopia } & Among groups & 3 & $0.22407 \mathrm{Va}$ & 11.29 \\
\hline & Populations within groups & 15 & $0.91011 \mathrm{Vb}$ & 45.84 \\
\hline & Within populations & 192 & $0.85103 \mathrm{Vc}$ & 42.87 \\
\hline & Total & 210 & 1.98520 & \\
\hline \multirow[t]{3}{*}{ Saudi Arabia } & Among regions & 2 & $0.02819 \mathrm{Va}$ & 3.34 \\
\hline & within regions & 182 & $0.81532 \mathrm{Vb}$ & 96.66 \\
\hline & Total & 184 & 0.84352 & \\
\hline \multirow[t]{4}{*}{ All countries } & Among countries & 5 & $0.14091 \mathrm{Va}$ & 8.88 \\
\hline & Populations within countries & 8 & $0.27001 \mathrm{Vb}$ & 17.01 \\
\hline & Within populations & 692 & $1.17663 \mathrm{Vc}$ & 74.12 \\
\hline & Total & 705 & 1.58755 & \\
\hline
\end{tabular}

S10). The dominant distribution pattern is unimodal, and the multimodal the is least frequent one among the populations. These results are compatible with the demographic expansion results from Table 4, which suggest demographic expansion, bottleneck or purifying selection.

Bayesian Skyline Plots show evidence of demographic expansion for all the countries in recent times, except for Pakistan (Fig. 4). Ethiopia shows evidence of a rapid population increase in recent years, much higher than the ones observed for Iraq, Libya, Saudi Arabia and Algeria.

\section{Discussion}

In this study, we analysed the mtDNA genetic diversity of 706 village chickens from Algeria, Ethiopia, Iraq, Libya, Pakistan and Saudi Arabia with the aim of unravelling their history and origin. To the best of our knowledge, it represents the first study on the D-loop mtDNA diversity of indigenous chicken from Algeria, Iraq and Libya. For Ethiopia, Pakistan and Saudi Arabia information about different populations (not included here) have been reported in another studies $[15,41,42]$.

The history of chicken domestication remains unsettled. The Indian subcontinent as well as South-East Asia have been proposed as major centres of origins of domestic chicken, with for the former the Indus Valley a possible centre of domestication. Accordingly, we would expect that Pakistani chicken would show the highest D-loop mtDNA diversity. This is not the case when we consider all haplogroups together for each country (Table 1). It is also not the case when examining only haplogroup $\mathrm{E}$ (Additional file 1: Table S6), believes to have its centre of diversity on the Indian subcontinent and with Liu et al. [14] reporting it as being the commonest one in Europe and India. Considering all haplogroups or only haplogroup E, Ethiopia displays the largest diversity. This may be a consequence of the number of chickens examined here, with more than twice as many Ethiopian than Pakistani samples. Alternatively, or in addition, it may reflect multiple arrivals of chicken in East Africa following different dispersal routes.

Interestingly, previous studies have suggested a possible dual origin for the chicken of East Africa [15, 43], with a terrestrial origin from the Indian subcontinent but also a genetic influence from South-East Asian chickens following maritime trading routes across the Indian Ocean. The second most-frequent haplogroup is haplogroup $\mathrm{D}$, postulated to be a legacy of the past Indian Ocean maritime trading networks [14]. This haplogroup is commonly observed in Ethiopian samples (Table 2), where it is more frequent in the southern region. It is completely absent in Libya and Algeria, and observed, but at a low frequency, in Iraq, Pakistan and Saudi Arabia. Such geographic distribution agrees with maritime routes of dispersal for this haplogroup across the Indian Ocean. Also, the absence of haplogroup D in Algeria and Libya, its relatively low frequency in other countries and its geographic distribution 
Table 4 Neutrality and demographic expansion parameters

\begin{tabular}{|c|c|c|c|c|c|c|}
\hline Population/Country & $\mathrm{N}$ & $S$ & MAE & Tajima's D ( $\boldsymbol{P}$-value) & Fu's $\boldsymbol{F s}$ (P-value) & Harpending r(P-value) \\
\hline \multicolumn{7}{|l|}{$\begin{array}{l}\text { Iraqi populations } \\
\text { North-East }\end{array}$} \\
\hline Sulimania [1] & 9 & 0 & 0 & $0(1.000)$ & $0(0)$ & $0(0)$ \\
\hline \multicolumn{7}{|l|}{ Central } \\
\hline Baghdad & 51 & 18 & 0.564 & $-0.653(0.280)$ & $-1.380(0.290)$ & $0.123(0.774)$ \\
\hline Karbala & 12 & 5 & 0.439 & $0.0918(0.567)$ & $0.538(0.616)$ & $0.155(0.423)$ \\
\hline Central [2] & 63 & 20 & 0.440 & $-0.911(0.208)$ & $-2.541(0.166)$ & $0.067(0.469)$ \\
\hline \multicolumn{7}{|l|}{ South } \\
\hline Basra & 11 & 1 & 0.055 & $-1.128(0.137)$ & $-0.410(0.350)$ & $0.438(0.942)$ \\
\hline Misan & 24 & 11 & 0.502 & $-1.824(0.016)$ & $-0.090(0.469)$ & $0.203(0.632)$ \\
\hline South [3] & 35 & 12 & 0.440 & $-2.074(0.001)$ & $-1.444(0.161)$ & $0.252(0.688)$ \\
\hline Total & 107 & 22 & 0.432 & $-1.090(0.134)$ & $-5.070(0.050)$ & $0.055(0.328)$ \\
\hline \multicolumn{7}{|c|}{$\begin{array}{l}\text { Algerian populations } \\
\text { North-West }\end{array}$} \\
\hline Mascara & 20 & 3 & 0.270 & $-1.440(0.032)$ & $-2.135(0.009)$ & $0.187(0.237)$ \\
\hline Oran & 17 & 5 & 0.560 & $-1.301(0.077)$ & $-2.953(0.001)$ & $0.211(0.536)$ \\
\hline Tiaret & 11 & 2 & 0.391 & $-1.429(0.037)$ & $0.506(0.622)$ & $0.735(0.933)$ \\
\hline Tlemcen & 18 & 15 & 0.557 & $-1.842(0.015)$ & $-2.089(0.088)$ & $0.053(0.128)$ \\
\hline North-West [1] & 66 & 19 & 0.308 & $-2.255(0.000)$ & $-7.246(0.000)$ & $0.066(0.096)$ \\
\hline \multicolumn{7}{|l|}{ Central } \\
\hline Adrar [2] & 22 & 5 & 0.547 & $0.0671(0.586)$ & $0.928(0.742)$ & $0.280(0.798)$ \\
\hline Total & 88 & 20 & 0.287 & $-2.092(0.001)$ & $-6.980(0.004)$ & $0.045(0.048)$ \\
\hline \multicolumn{7}{|c|}{$\begin{array}{l}\text { Ethiopian populations } \\
\text { North }\end{array}$} \\
\hline Meseret & 10 & 11 & 0.609 & $-1.202(0.139)$ & $-0.944(0.237)$ & $0.064(0.138)$ \\
\hline Mihquan & 10 & 9 & 0.838 & $-1.411(0.080)$ & $2.172(0.898)$ & $0.226(0.701)$ \\
\hline North [1] & 20 & 14 & 0.503 & $-1.390(0.088)$ & $-0.596(0.419)$ & $0.067(0.269)$ \\
\hline \multicolumn{7}{|l|}{ Central-East } \\
\hline Adane & 10 & 11 & 0.757 & $-0.741(0.272)$ & $0.505(0.600)$ & $0.176(0.655)$ \\
\hline Arabo & 10 & 4 & 0.786 & $-0.339(0.414)$ & $-1.629(0.051)$ & $0.185(0.462)$ \\
\hline Horro & 30 & 10 & 0.782 & $0.219(0.638)$ & $2.383(0.867)$ & $0.125(0.647)$ \\
\hline Jarso & 14 & 0 & 0 & $0(0)$ & $0(0)$ & $0(0)$ \\
\hline Midir & 10 & 2 & 0.586 & $-0.183(0.322)$ & $-0.272(0.360)$ & $0.240(0.509)$ \\
\hline Negasi Amba & 10 & 1 & 0.297 & $0.819(0.853)$ & $0.818(0.672)$ & $0.222(0.340)$ \\
\hline Central-East [2] & 84 & 20 & 0.781 & $-0.239(0.497)$ & $1.547(0.786)$ & $0.103(0.748)$ \\
\hline \multicolumn{7}{|l|}{ West } \\
\hline Amshi & 10 & 1 & 0.371 & $1.302(0.919)$ & $1.029(0.789)$ & $0.288(0.612)$ \\
\hline Ashuda & 10 & 1 & 0.186 & $0.014(0.754)$ & $0.417(0.670)$ & $0.209(0.326)$ \\
\hline Batambie & 8 & 1 & 0.100 & $-1.054(0.187)$ & $-0.182(0.446)$ & $0.312(0.792)$ \\
\hline Dikuli & 10 & 2 & 0.586 & $-0.183(0.355)$ & $-0.272(0.374)$ & $0.240(0.531)$ \\
\hline Gafera & 10 & 1 & 0.297 & $0.819(0.827)$ & $0.818(0.698)$ & $0.222(0.366)$ \\
\hline Surta & 9 & 1 & 0.080 & $-1.088(0.157)$ & $-0.263(0.389)$ & $0.358(0.918)$ \\
\hline Tzion Teguaz & 10 & 3 & 0.342 & $-0.431(0.331)$ & $0.345(0.571)$ & $0.133(0.180)$ \\
\hline West [3] & 67 & 5 & 0.578 & $-0.104(0.497)$ & $-2.569(0.092)$ & $0.124(0.290)$ \\
\hline
\end{tabular}


Table 4 Neutrality and demographic expansion parameters (Continued)

\begin{tabular}{|c|c|c|c|c|c|c|}
\hline Population/Country & $\mathrm{N}$ & $S$ & MAE & Tajima's D ( $\boldsymbol{P}$-value) & Fu's Fs (P-value) & Harpending $\mathrm{r}(\boldsymbol{P}$-value $)$ \\
\hline \multicolumn{7}{|l|}{ South } \\
\hline Girissa & 10 & 4 & 0.487 & $-0.942(0.204)$ & $-2.096(0.019)$ & $0.073(0.081)$ \\
\hline Kumato & 10 & 10 & 0.819 & $-0.364(0.361)$ & $0.505(0.583)$ & $0.144(0.527)$ \\
\hline Loya & 10 & 8 & 0.627 & $1.076(0.865)$ & $0.706(0.646)$ & $0.082(0.250)$ \\
\hline Shubi Gemo & 10 & 14 & 0.721 & $0.746(0.798)$ & $0.723(0.616)$ & $0.159(0.757)$ \\
\hline South [4] & 40 & 23 & 0.653 & $0.345(0.703)$ & $-4.181(0.083)$ & $0.020(0.118)$ \\
\hline Total & 211 & 33 & 0.573 & $-0.938(0.176)$ & $-15.722(0.001)$ & $0.045(0.364)$ \\
\hline \multicolumn{7}{|l|}{ Saudi Arabia } \\
\hline East [1] & 45 & 18 & 0.729 & $-1.964(0.006)$ & $-9.069(0.000)$ & $0.132(0.494)$ \\
\hline Central [2] & 43 & 20 & 0.231 & $-2.207(0.001)$ & $-4.717(0.014)$ & $0.048(0.096)$ \\
\hline West [3] & 97 & 23 & 0.314 & $-1.862(0.009)$ & $-7.33(0.007)$ & $0.062(0.200)$ \\
\hline Total & 185 & 34 & 0.375 & $-2.115(0.000)$ & $-18.713(0.000)$ & $0.061(0.186)$ \\
\hline \multicolumn{7}{|l|}{ Other populations } \\
\hline Libya & 23 & 14 & 0.520 & $-1.539(0.047)$ & $-3.704(0.018)$ & $0.058(0.183)$ \\
\hline Pakistan & 92 & 24 & 0.547 & $-0.861(0.210)$ & $-4.096(0.085)$ & $0.063(0.482)$ \\
\hline \multicolumn{7}{|l|}{ Total } \\
\hline All the samples included in this study & 706 & 55 & 0.323 & $-1.668(0.013)$ & $-97.654(0.000)$ & $0.025(0.096)$ \\
\hline
\end{tabular}

in Ethiopia is suggesting that the arrival and dispersal of the D haplogroup may have occurred after the North and Western dispersal of haplogroup E.

Within countries, we observed a different level of diversity across regions. Iraqi chicken populations from the Central area show more diversity than the two populations from the South of the country (Table 1). High genetic diversity in the Central region may be attributed to terrestrial inland route of dispersion and arrival of domestic chicken in the country rather than a maritime arrival in the South of the country. Also, it is worth remembering that the central area of the country includes the capital Baghdad, a city built during the eighth century as the capital of the Abbasid Caliphate. Accordingly, the region might have witnessed major movements of populations and their livestock from different geographic areas across time. Alternatively, it remains possible that domestic chicken may have reached today Iraq following a maritime trading route with subsequent admixture of populations more recently.

In Algeria, apart from one haplotype belonging to haplogroup A, only haplogroup E was observed. Diversity between the northern part of the country and the more central region is nearly the same. The populations studied here are geographically close to each other and in such context, the results might not be surprising. Examination of other populations from other parts of the country is needed to investigate whether Algerian chickens represent a single genetic group or not. In Libya, we only analysed a single population, and as for Algeria, only two haplogroups were observed, with haplogroup E being the commonest. Together, these results support a main Indian subcontinent origin for the chickens of these two countries and by extension to the shores of the Mediterranean Sea. It may have followed inland terrestrial routes throughout the Fertile Crescent or a more direct one through the Red Sea and Egypt.

Saudi Arabian populations show the presence of four haplogroups (A, C, D and E), with E the commonest. This probably reflects more than one route of introduction and origin for the Saudi Arabian chicken. Haplogroup E likely originated from the Indian subcontinent following a terrestrial and maritime route while other haplogroups may have reached the country following maritime trading network on the Arabian Gulf and the Red Sea. This is further supported by the genetic diversity values observed for the different regions, where the eastern part on the Arabian Gulf shows higher diversity $(0.856 \pm 0.044)$ compared to the central $(0.631 \pm 0.084)$ and western $(0.702 \pm 0.041)$ regions of the country.

Five haplogroups (A, B, C, D and E) have been identified in Ethiopian populations, with possibly different historical backgrounds of introduction. As mentioned before, the $\mathrm{E}$ haplogroup, the commonest, probably originated from the Indian subcontinent via either a terrestrial route along the Nile River Basin and/or arrival through the coastal areas of the Horn of Africa. The latter was the most likely route for the second most frequent haplogroup D. Within the country, the South region displays the highest haplotype $(0.929 \pm 0.021)$ and nucleotide $(0.0150 \pm 0.0006)$ variations compared to the other three Ethiopian regions. Then the Central - East, North and West regions with little differences among them. 

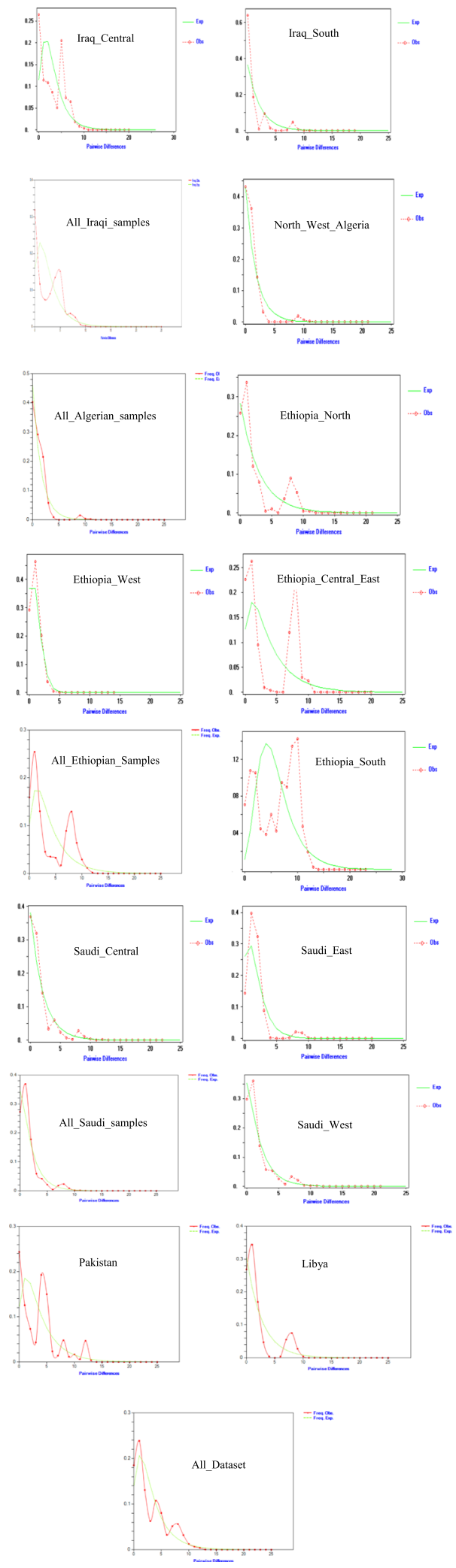

Fig. 3 Mismatch distribution patterns for regions and countries
Compared to other studies, the $D$-loop mtDNA diversity of Ethiopian, Iraqi, Libyan, Pakistani and Saudi chickens are higher than those previously reported for Iranian, Turkey and Egyptian chickens in the literature [44-46]. Similarly, among sub-Saharan chicken populations studied previously, we observe higher genetic diversity for the countries included in this study compared with populations from Nigeria, Chad, Uganda and Sudan [15, 22, 47]. These results need to be interpreted with caution considering difference in number of samples examined here. Nevertheless, for these other countries haplogroup E remains by far the commonest, with other haplogroups either rare or absent supporting our previous conclusion of arrival of haplogroup E on the African continent before other haplogroups. The high mtDNA diversity of Ethiopian chickens not only reflects extensive ancient livestock movements following trading routes linking Ethiopia to the Fertile Crescent civilisations, it also highlights the importance of the Horn of Africa as an entry point of livestock into the continent.

A high frequency of one haplotype $\left(H_{-} \_3\right)$ was found in all countries examined here (Fig. 2), which likely represent an ancestral E haplotype. Most samples were clustered in haplogroup $\mathrm{E}$, while haplogroup A, $B, C$ and $D$ were observed at low frequencies. Hap$\operatorname{logroup} \mathrm{E}$ and $\mathrm{A}$ were found in all the studied countries. Haplogroup B was found only in Ethiopia, represented by just one individual in the Mihquan population. Haplogroup C is present in Saudi Arabian and Ethiopian samples only, and specifically in the south-western region on the shores of the Red Sea (Abhaa and Jazan) in Saudi Arabia and in the south region (Loya) of Ethiopia. Haplogroups A and B have been reported before mainly from South China [14]. Haplogroup $C$ was originally observed in chickens from Japan and South-East China dispersing through the maritime ancient trading network [14]. The origins of these haplogroups present a low frequency in our dataset remains speculative; they may be a legacy of ancient dispersal and/or more recent crossbreeding with commercial birds.

Overall, AMOVA showed similarity among countries, with most of the variation observed among individuals within populations (Table 3). However, more variation among populations within groups are observed for Ethiopia and Iraq in comparison to other countries. This supports our interpretation of haplotypes and haplogroups diversity discussed above, suggesting in particular for Ethiopia that multiple routes of chicken dispersal have occurred. It also indicates that once domestic chicken reached a country, genetic exchanges occurred within the country, limiting the usefulness of the $D$-loop mitochondrial DNA as a genetic marker for phylogeographic analysis within country. 


\section{Baysian Skyline Plot for all the studied countries}

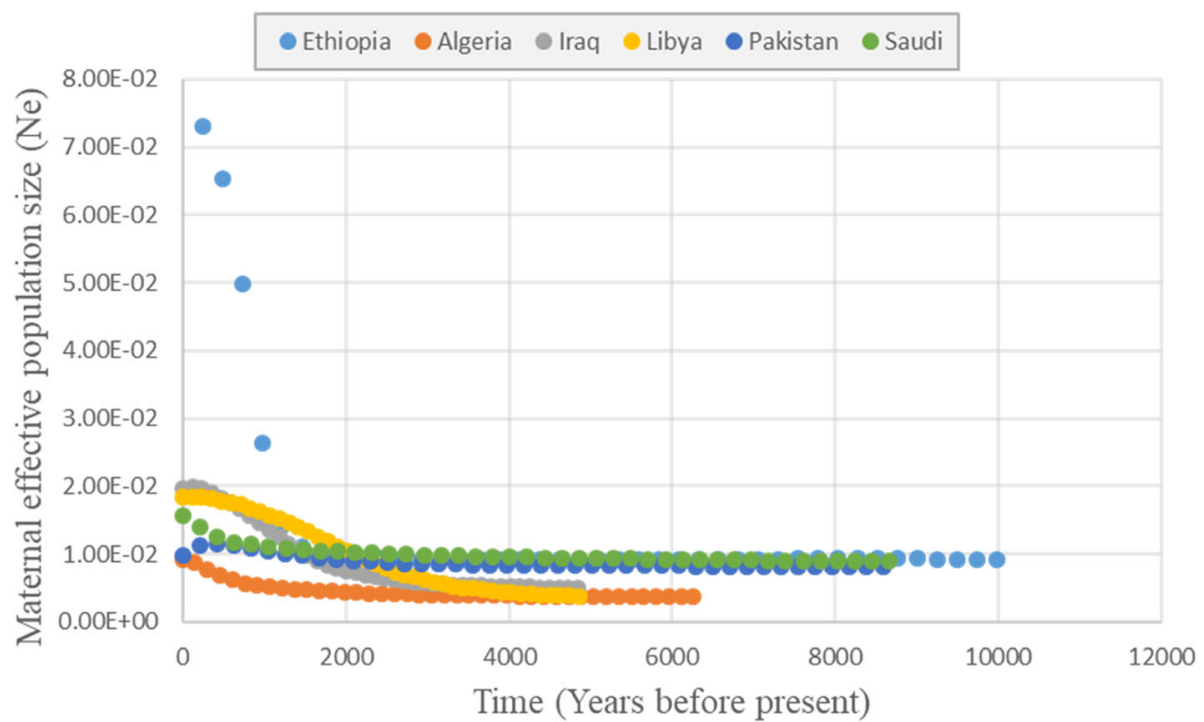

Fig. 4 Bayesian Skyline Plot (BSP) for the countries. Points for each country represent the estimated effective population size at different time point

\section{Conclusion}

This paper presents for the first time the genetic diversity of Algerian, Iraqi and Libyan indigenous chickens using mtDNA $D$-loop sequencing information. Combined with findings from other studies, the results presented here add further support for a main Indian subcontinent origin for chickens of the countries examined here, as well as for the importance of the Indian Ocean maritime trading network for the dispersal of the species. However, no or low phylogeographic structure was observed overall across the studied populations, showing the limitation of the $D$-loop chicken mitochondrial DNA diversity for this purpose.

\section{Methods}

\section{Collection of samples and genomic DNA isolation}

This study was conducted on 706 samples. It includes chicken from Pakistan $(n=92)$, Iraq $(n=107)$, Libya $(n=23)$, Saudi Arabia $(n=185)$, Algeria $(n=88)$ and Ethiopia $(n=211)$. Iraqi samples were collected from five different areas (Fig. 5) divided into three groups: (i) North, represented by Sulimania $(n=9)$ in the NorthEast part of Iraq; (ii) Central with two sampling locations in the central region of Iraq, Baghdad $(n=51)$ and Karbala $(n=12)$; and (iii) South with two regions in the South-East and southern part of the country, Misan $(n=$ $24)$ and Basra $(n=11)$. In Saudi Arabia, samples were collected from 17 sites divided into three groups, East (Al-Qatef, Hafar Al-Batin and Al-Hessa $(n=45)$ ), Central (Hail, Al-Aflaj, Al-Kharj, Al-Amariah and Unayzah $(n=43))$ and West (Abha, Al-Baha, Jeddah, Jazan, Mecca, Medina, Najran, Tabuk and Taif, $(n=97))$.
Algerian chicken samples were divided into two groups, North (Mascara $(n=20)$, Oran $(n=17)$, Tiaret $(n=11)$ and Tlemcen $(\mathrm{n}=18))$ and Central (Adrar $(n=22))$. Due to the political situation, sampling in Libya was limited to one population representing the North-West part of the country along the Mediterranean Sea.

In Ethiopia, chicken samples were collected from 19 different sites from both the highland and lowland parts of the country. Ten samples from each site were examined except for four populations (Batambie $\mathrm{n}=8$, Horro $n=30$, Jarso $n=14$ and Surta $n=9$ ). The Ethiopian populations were divided into four groups: North (Meseret and Mihquan), Central-East (Adane, Arabo, Horro, Jarso, Midir and Negasi Amba), West (Ashuda, Amshi, Batambie, Dikuli, Gafera, Surta and Tzion Teguaz) and South (Kumato, Loya, Shubi Gemo and Girissa). All the blood samples were collected from free-range scavenging or semi-scavenging village chickens following standard veterinary practice approved by the relevant authority in each country and written or verbal consent from the farmers to sample their birds.

\section{DNA extraction, PCR amplification and sequence alignment}

Total genomic DNA was extracted from air-dried blood preserved on FTA classic cards (FTA ${ }^{\circ}$ cards) (Whatman Biosciences) using the MACHEREY-NAGEL DNA extraction kit or from full blood preserved in ethanol using the Qiagen kit following the manufacturers' instructions.

Five hundred and forty-nine base pairs of the mtDNA $D$-loop region were amplified using AV1F2 (5'-AGGACT 


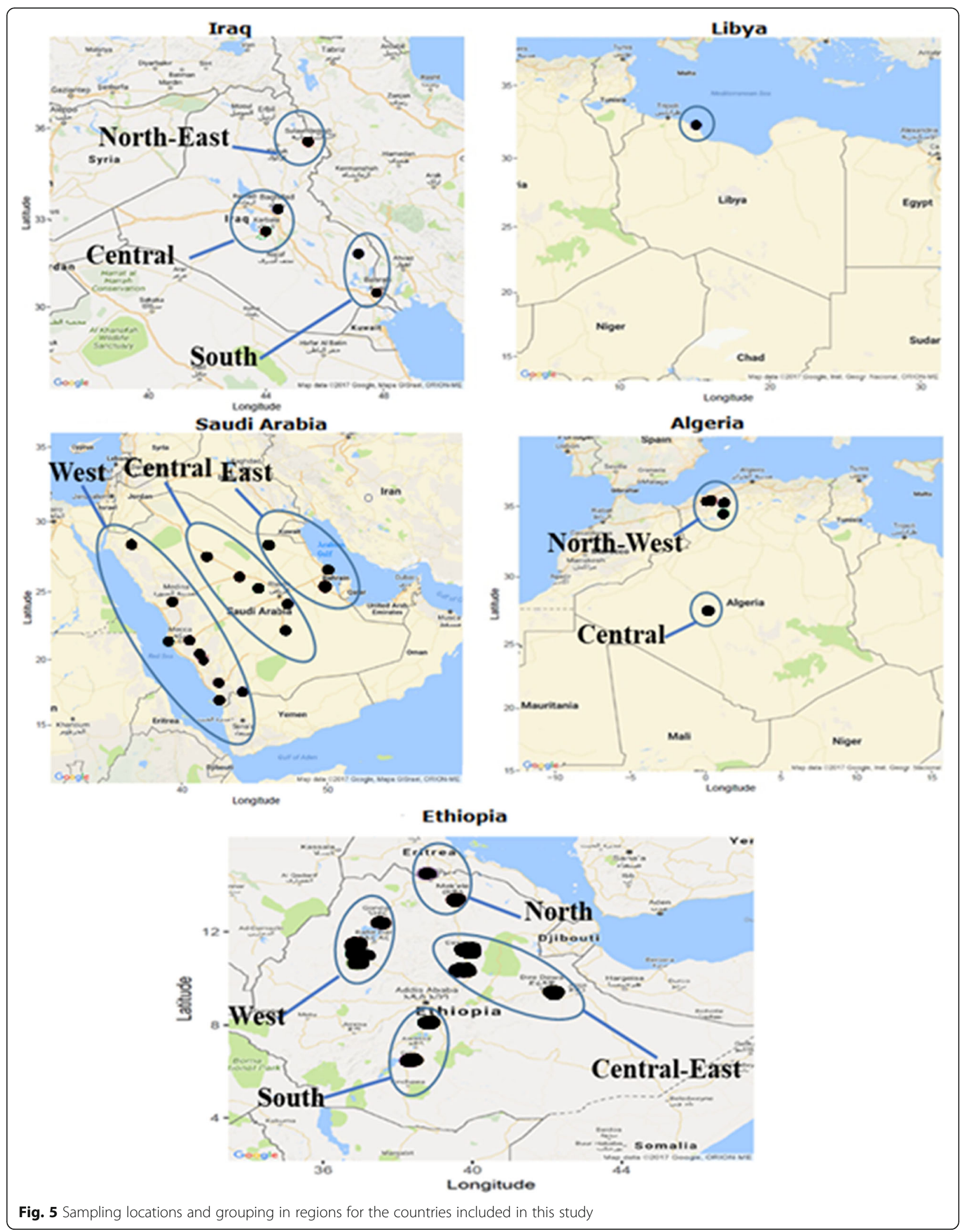


ACGGCTTGAAAAGC-3') [15] as the forward primer, and H547 (5' - ATGTGCCTGACCGAGGAACCAG-3') [16] as the reverse primer. PCR amplifications were carried out in a $20-\mu \mathrm{l}$ reaction volume containing 40 ng genomic DNA, $10 \mu \mathrm{l}$ PCR ready master mix (Thermo Scientific Ltd), $0.5 \mu \mathrm{M}$ of each primer, and sterile nuclease-free water to reach the final volume of $20 \mu$ l. The PCR was carried out using a Peltier thermocycler with the following conditions: Hot lid $\left(110^{\circ} \mathrm{C}\right)$, hot start $98^{\circ} \mathrm{C}$ $(30 \mathrm{~s})$, denaturation $98^{\circ} \mathrm{C}(5 \mathrm{~s})$, annealing $63^{\circ} \mathrm{C}(5 \mathrm{~s})$, elongation $72^{\circ} \mathrm{C}(10 \mathrm{~s}), 35$ cycles and final extension step at $72^{\circ} \mathrm{C}(1 \mathrm{~min})[17-19]$. The PCR product was electrophoresed on a $1 \%$ agarose gel at $100 \mathrm{~V}$ for 45 min, and then the gel was stained by $1 \%$ ethidium bromide and visualised under ultraviolet light. Amplified DNA fragment size was estimated through size comparison with a $1 \mathrm{~kb}$ DNA ladder from New England BioLabs loaded alongside the PCR products. The products were purified using the reSource PCR purification kit from Source Bioscience.

An Applied Biosystems 3730 DNA Analyser was used for Sanger sequencing. For each sample, the primer sequences were trimmed to generate the 549-bp sequence fragment and correct possible base-calling errors using the proseq 3 version 3.5 software [20]. Sequences were aligned to the chicken mtDNA reference sequence (GenBank accession no. AB098668) [16] using Clustal $\mathrm{X}$ version 2.1 [21]. Analyses were restricted to the first $397 \mathrm{bp}$ of the sequence, which includes the hypervariable region (HV1) of the D-loop [22]. This dataset for the six countries was deposit in GenBank sequence database (https://www.ncbi.nlm.nih.gov/genbank/), accession numbers MK920994-MK921699.

For all the Ethiopian and some of the Iraqi samples $(n=22)$, the full mtDNA was retrieved from full-genome sequencing data using the Genome Analysis Toolkit (GATK V3.7) [23, 24]. The sequences were then aligned with the chicken mtDNA reference genome sequence and the $397 \mathrm{bp}$ of the $D$-loop selected for further analysis.

\section{Genetic diversity estimation}

DnaSP v5 was used to identify polymorphic sites, the number of haplotypes and to calculate haplotype diversity $(\mathrm{Hd})$, nucleotide diversity $(\pi)$ and the average number of nucleotide differences [25]. These parameters were examined both at population and country levels. The statistical significant differences for haplotype and nucleotide diversities were tested following Alexander et al. [26] methodology.

\section{Phylogenetic analysis}

In order to assess the possible phylogeographic origin of the samples, reference sequences from Liu et al. [14] haplogroups were included (AB114069 - haplogroup A,
AB007744 - haplogroup B, AB114070 - haplogroup C, AY588636 - haplogroup D, AB114076 - haplogroup E, AF512285 - haplogroup F, AF512288 - haplogroup G, D82904 - haplogroup H, and AB009434 - haplogroup I). The phylogenetic tree was constructed using jModeltest version 2.1.7 [27] to predict the best-fit model and Phyml version 3.0 for the maximum likelihood tree [28]. The confidence level for each branch in the tree was assessed with 1000 bootstrap replications. To infer the relationship between the haplotypes, Median-Joining (MJ) network was built using the NETWORK 5.0.0 [29] and the PopArt [30]. To further illustrate the ancient migratory routes of chicken, 775 sequences from Chad, Egypt, Nigeria, Sudan, Turkey and Iran were downloaded from GeneBank (Table S1).

\section{Analysis of molecular variance (AMOVA)}

The analysis of molecular variance was implemented using Arlequin v 3.5.2 with 1000 permutations [31]. It was performed across countries and within countries. Across countries, the analysis was performed using all the samples in a country with each country as an individual group. For within-country analyses, we followed the grouping of the populations as described in the sampling section, namely Iraqi samples were divided into three groups (Central $n=$ 63 , North $n=9$, South $n=35$ ), Algerian samples were divided into two groups, (North-West and Central). Ethiopian samples were divided into four groups ((Meseret and Mihquan), (Adane, Arabo, Horro, Jarso, Midir and Negasi Amba), (Ashuda, Amshi, Batambie, Dikuli, Gafera, Surta, and Tzion Teguaz), and (Girissa, Kumato, Loya, Shubi Gemo)), and Saudi Arabian were divided into three groups (East $(n=45)$, Central $(n=43)$ and West $(n=97))$. All Libyan and Pakistani samples were grouped as a single Libyan or Pakistani country population.

\section{Neutrality test and demographic dynamics}

The demographic profiles for each population were calculated from mismatch distribution patterns [32]. The Mean Absolute Error (MAE) was calculated between the observed and the theoretical (expected) mismatch distributions to provide support for demographic expansion [33]. Then, Fu's Fs [34] and Tajima's D [35] were estimated using the infinite site model in DnaSP v.5 [25].

Bayesian Skyline Plots (BSPs) [36] were investigated in order to have deeper insight into the demographic history of the chicken within countries. It was accomplished using the piecewise constant function in BEAST V 2.4.7 [37]. First, the $\mathrm{HKY}+\mathrm{G}$ nucleotide substitution model was used for the analysis and then separate Markov Chain Monte Carlo simulation (MCMC) runs were applied for twenty-million generations sampled every one-thousand generations with the first two-million generations used as burn-in. Tracer software V.1.7 [38] was used to calculate 
the convergence of the posterior estimates of $\mathrm{Ne}$ to the likelihood of stationary distribution. The BSPs were standardised using the molecular mutation rate of evolution for chicken mtDNA, $3.13 \times 10^{-7}$ mutations/site/year $(\mathrm{m} /$ $\mathrm{s} / \mathrm{y}$ ) following Alexander et al. [39]. This estimation of BSPs was performed on each country samples separately and they were then plotted together.

\section{Supplementary information}

Supplementary information accompanies this paper at https://doi.org/10. 1186/s12863-020-0830-0.

Additional file 1: Fig. S1. mtDNA D-loop variation of 88 haplotypes found in the 706 village chicken. Fig. S2. Median-Joining network for Algerian haplotypes $(n=13)$. Fig. S3. Median-Joining network for Ethiopian haplotypes $(n=36)$. Fig. S4. Median-Joining network for Iraqi haplotypes $(n=18)$. Fig. S5. Median-Joining network for Libyan haplotypes $(n=10)$. Fig. S6. Median-Joining network for Pakistani haplotypes $(n=19)$. Fig. S7. Median-Joining network for Saudi Arabia haplotypes $(n=26)$. Fig. S8. Maximum likelihood tree for the 136 haplotypes and references from Liu et al. [14]. Fig. S9. Median-Joining network for 136 haplotypes of the collected and downloaded samples. Fig. S10. Mismatch distribution patterns of populations included in this study. Table S1. Downloaded sequences from GeneBank. Table S2a. Haplotype diversity significant differences among Iraqi populations. Table $\mathbf{S 2} \mathbf{b}$. Nucleotide diversity significant differences among Iraqi populations. Table S3a. Haplotype diversity significant differences among Algerian populations. Table S3b. Nucleotide diversity significant differences among Algerian populations. Table S4a. Haplotype diversity significant differences among Ethiopian populations. Table S4b. Nucleotide diversity significant differences among Ethiopian populations. Table S5a. Haplotype diversity significant differences among Saudi regions. Table S5b. Nucleotide diversity significant differences among Saudi regions. Table S6. Location, sample size and genetic diversity of haplogroup $E$.

\section{Abbreviations}

AMOVA: Analysis of Molecular Variances; BSP: Bayesian Skyline Plot; FTA Cards: Flinders Technology Associates Cards; GATK: Genome Analysis Toolkit; Hd: Haplotype diversity; MAE: Mean Absolute Error; MCMC: Markov Chain Monte Carlo; MJ: Median-Joining; PCR: Polymerase Chain Reaction;

Nucleotide diversity

\section{Acknowledgments}

This study is part of the first author (Ahmed S. Al-Jumaili) PhD, supported and funded by the Iraqi Ministry of Higher Education and Scientific Research (MOHESR). Special thanks to Ahmed Saadi for contributing Karbala samples from Iraq.

\section{Authors' contributions}

A.S.A. and O.H. designed the project, and A.S.A. contributed to all data analysis. S.A.A. and A.A.E. contributed the Iraqi samples. A.A. contributed the Libyan samples from Misurata. R.M.A and R.S.A collected the samples of the Saudi Arabia chicken. S.F.B. and S.B.S.G. have provided all the Algerian samples. Pakistani samples and their sequences were contributed by G. B. and A. N. N. The manuscript was prepared by A.S.A. and revised by O.H. All author(s) read and approved the final manuscript.

\section{Funding}

This research was funded in part by the Bill and Melinda Gates Foundation and with UK aid from the UK Government's Department for International Development (Grant Agreement OPP1127286) under the auspices of the Centre for Tropical Livestock Genetics and Health (CTLGH), established jointly by the University of Edinburgh, SRUC (Scotland's Rural College), and the International Livestock Research Institute (ILRI). The findings and conclusions contained within are those of the authors and do not necessarily reflect positions or policies of the Bill \& Melinda Gates Foundation nor the UK Government. The study has benefitted from the support of the CGIAR
Livestock CRP. Sampling of the Saudi chickens was supported through a grant (12-AGR2555-02) from the National Plan for Science, Technology and Innovation (MAARIFAH), King Abdulaziz City for Science and Technology, Kingdom of Saudi Arabia. The funding bodies played no role in the design of the study and collection, analysis, and interpretation of data and in writing the manuscript.

\section{Availability of data and materials}

The datasets generated and/or analysed during the current study are available in the GenBank repository, [https://www.ncbi.nlm.nih.gov/genbank/] accession numbers MK920994-MK921699.

\section{Ethics approval and consent to participate}

This study was approved by the ethics committee of International Livestock Research IAUC guidelines (Reference Number IACUC-RC2017-21) and the Ethics committee of Iraqi Ministry of Higher Education and Ministry of Agriculture (Reference Number 17352015/2872).

\section{Consent for publication}

Not applicable.

\section{Competing interests}

The authors declare that they have no competing interests.

\section{Author details}

${ }^{1}$ School of Life Sciences, the University of Nottingham, University Park, Nottingham NG7 2RD, UK. ² University of Anbar, Ministry of Higher Education and Scientific Research, Anbar, Iraq. '3aboratoire de Génétique Moléculaire et Cellulaire, Université des Sciences et de la Technologie d'Oran Mohamed Boudiaf, USTO-MB, BP 1505, El M'naouer, Oran 31000, Algérie. ${ }^{4}$ Amhara Regional Agricultural Research Institute (ARARI), P.O. Box:527 Code 100, Bahir Dar, Ethiopia. ${ }^{5}$ LiveGene, International Livestock Research Institute (ILRI), P. O. 5689, Addis Ababa, Ethiopia. ${ }^{6}$ Animal Sources Department, Directorate of Animal Resources, Ministry of Agriculture, Baghdad, Iraq. ${ }^{7}$ Animal Biotechnology, Animal Science Department, College of Food and Agriculture, King Saud University, P.O.Box 246, Riyadh 11451, Kingdom of Saudi Arabia. ${ }^{8}$ Genetics and Biotechnology, Animal Science Department, Agriculture Faculty, Mutah University, Karak, Jordan. ${ }^{9}$ Small Ruminant Genetics and Genomics Group, International Centre for Agricultural Research in the Dry Areas (ICARDA), P.O. Box 5689, ILRI-Ethiopia Campus, Addis Ababa, Ethiopia. ${ }^{10}$ Department of Forensic Sciences, Oslo University Hospital, Oslo, Norway. ${ }^{11}$ Faculty of Life Sciences, Karakorum International University, Gilgit Baltistan, Pakistan. ${ }^{12}$ Physiopathology and Biochemical of Nutrition (PpBioNut), University of Tlemcen, Tlemcen, Algeria.

Received: 24 May 2019 Accepted: 25 February 2020

Published online: 14 March 2020

References

1. Leta S, Endalew B. Survey on village based chicken production and utilization system in mid Rift Valley of Oromia, Ethiopia. Glob Vet. 2010;5(4): 198-203.

2. Gueye $\mathrm{E}$. The role of networks in information dissemination to family poultry farmers. Worlds Poult Sci J. 2009;65(1):115-24.

3. Darwin C. In: Murray J, editor. The variation of animals and plants under domestication. 2nd ed. United Kingdom: John Murray; 1868.

4. Al-Rawi A, Al-Athari A. Characteristics of indigenous chicken in Iraq. Anim Genet Resour. 2002;32:87-93.

5. Al-Yousef YM. A survey study on the distribution of Saudi Baladi chickens and their characteristics. Int J Poult Sci. 2007;6(2):289-92.

6. Dalhoum L, Moula N, Halbouche M, Mignon-Grasteau S. Phenotypic characterization of the indigenous chickens (Gallus gallus) in the northwest of Algeria. Arch Anim Breed. 2016;59:79-90.

7. Lawal RA, Al-Atiyat RM, Aljumaah RS, Silva P, Mwacharo JM, Hanotte O. Whole-genome resequencing of red junglefowl and indigenous village chicken reveal new insights on the genome dynamics of the species. Front Genet. 2018;9:1-17.

8. Dyomin A, Danilova M, Mwacharo J, Masharsky A, Panteleev A, Druzhkova A, et al. Mitochondrial DNA D-loop haplogroup contributions to the genetic diversity of east European domestic chickens from Russia. J Anim Breed Genet. 2017;134(2):98-108. 
9. Miao Y, Peng M, Wu G, Ouyang Y, Yang Z, Yu N, et al. Chicken domestication: an updated perspective based on mitochondrial genomes. Heredity. 2013;110(3):277

10. Di Lorenzo P, Ceccobelli S, Panella F, Attard G, Lasagna E. The role of mitochondrial DNA to determine the origin of domestic chicken. Worlds Poult Sci J. 2015;71(2):311-8.

11. Zeuner FE. A history of domesticated animals; 1963.

12. Woldekiros H, D'Andrea A. Early evidence for domestic chickens (Gallus gallus domesticus) in the horn of Africa. Int J Osteoarchaeol. 2017;27(3):329-41.

13. Galli M. Beyond frontiers: ancient Rome and the Eurasian trade networks. J Eurasian Stud. 2017:8(1):3-9.

14. Liu Y-P, Wu G-S, Yao Y-G, Miao Y-W, Luikart G, Baig M, et al. Multiple maternal origins of chickens: out of the Asian jungles. Mol Phylogenet Evol. 2006:38(1):12-9.

15. Mwacharo JM, Bjørnstad G, Mobegi V, Nomura K, Hanada H, Amano T, et al. Mitochondrial DNA reveals multiple introductions of domestic chicken in East Africa. Mol Phylogenet Evol. 2011;58(2):374-82.

16. Komiyama T, Ikeo K, Gojobori T. Where is the origin of the Japanese gamecocks? Gene. 2003;317:195-202.

17. Chester N, Marshak DR. Dimethyl sulfoxide-mediated primer tm reduction: a method for analyzing the role of renaturation temperature in the polymerase chain reaction. Anal Biochem. 1993;209(2):284-90.

18. Nord K, Gunneriusson E, Ringdahl J, Ståhl S, Uhlén M, Nygren P-Å. Binding proteins selected from combinatorial libraries of an a-helical bacterial receptor domain. Nat Biotechnol. 1997;15(8):772.

19. Wikman M, Steffen A-C, Gunneriusson E, Tolmachev V, Adams GP, Carlsson $J$, et al. Selection and characterization of HER2/neu-binding affibody ligands. Protein Eng Des Sel. 2004;17(5):455-62.

20. Filatov DA. Processing and population genetic analysis of multigenic datasets with ProSeq3 software. Bioinformatics. 2009;25(23):3189-90.

21. Thompson JD, Gibson TJ, Plewniak F, Jeanmougin F, Higgins DG. The CLUSTAL_ $X$ windows interface: flexible strategies for multiple sequence alignment aided by quality analysis tools. Nucleic Acids Res. 1997;25(24):4876-82.

22. Adebambo A, Mobegi V, Mwacharo J, Oladejo B, Adewale R, llori L, et al. Lack of Phylogeographic structure in Nigerian Village chickens revealed by mitochondrial DNA D-loop sequence analysis. Int J Poult Sci. 2010;9(5):503-7.

23. DePristo MA, Banks E, Poplin R, Garimella KV, Maguire JR, Hartl C, et al. A framework for variation discovery and genotyping using next-generation DNA sequencing data. Nat Genet. 2011;43(5):491.

24. Van der Auwera GA, Carneiro MO, Hartl C, Poplin R, Del Angel G, LevyMoonshine A, et al. From FastQ data to high-confidence variant calls: the genome analysis toolkit best practices pipeline. Curr Protoc Bioinformatics. 2013;43(1):11.0. 1-0. 33

25. Librado P, Rozas J. DnaSP v5: a software for comprehensive analysis of DNA polymorphism data. Bioinformatics. 2009;25(11):1451-2.

26. Alexander A, Steel D, Hoekzema K, Mesnick SL, Engelhaupt D, Kerr I, et al. What influences the worldwide genetic structure of sperm whales (Physeter macrocephalus)? Mol Ecol. 2016;25(12):2754-72.

27. Darriba D, Taboada GL, Doallo R, Posada D. jModelTest 2: more models, new heuristics and parallel computing. Nat Methods. 2012;9(8):772.

28. Guindon S, Gascuel O. A simple, fast, and accurate algorithm to estimate large phylogenies by maximum likelihood. Syst Biol. 2003;52(5):696-704.

29. Bandelt $\mathrm{H}-J$, Forster $P$, Röhl A. Median-joining networks for inferring intraspecific phylogenies. Mol Biol Evol. 1999;16(1):37-48.

30. Leigh JW, DJMiE B. Popart: full-feature software for haplotype network construction. Methods Ecol Evol. 2015;6(9):1110-6.

31. Excoffier $L$, Lischer HE. Arlequin suite ver 3.5: a new series of programs to perform population genetics analyses under Linux and windows. Mol Ecol Resour. 2010;10(3):564-7.

32. Rogers $A R$, Harpending $H$. Population growth makes waves in the distribution of pairwise genetic differences. Mol Biol Evol. 1992;9(3):552-69.

33. Rogers AR, Fraley AE, Bamshad MJ, Watkins WS, Jorde LB. Mitochondrial mismatch analysis is insensitive to the mutational process. Mol Biol Evol. 1996;13(7):895-902.

34. Fu Y-X. Statistical tests of neutrality of mutations against population growth, hitchhiking and background selection. Genetics. 1997;147(2):915-25.

35. Tajima F. Statistical method for testing the neutral mutation hypothesis by DNA polymorphism. Genetics. 1989;123(3):585-95.

36. Drummond AJ, Rambaut A, Shapiro B, Pybus OG. Bayesian coalescent inference of past population dynamics from molecular sequences. Mol Biol Evol. 2005;22(5):1185-92.
37. Bouckaert R, Heled J, Kühnert D, Vaughan T, Wu C-H, Xie D, et al. BEAST 2: a software platform for Bayesian evolutionary analysis. PLoS Comput Biol. 2014;10(4):e1003537.

38. Rambaut A, Drummond AJ, Xie D, Baele G, Suchard MA. Posterior summarization in Bayesian phylogenetics using tracer 1.7. Syst Biol. 2018; 67(5):901-4.

39. Alexander M, Ho SY, Molak M, Barnett R, Carlborg Ö, Dorshorst B, et al. Mitogenomic analysis of a 50-generation chicken pedigree reveals a rapid rate of mitochondrial evolution and evidence for paternal mtDNA inheritance. Biol Lett. 2015;11(10):20150561.

40. Ramos-Onsins SE, Rozas J. Statistical properties of new neutrality tests against population growth. Mol Biol Evol. 2002;19(12):2092-100.

41. Herrera MB, Thomson VA, Wadley JJ, Piper PJ, Sulandari S, Dharmayanthi AB, et al. East African origins for Madagascan chickens as indicated by mitochondrial DNA. R Soc Open Sci. 2017;4(3):160787.

42. Nisar A, Waheed A, Khan S, Feng X, AHJMDPA S. Population structure, genetic diversity and phylogenetic analysis of different rural and commercial chickens of Pakistan using complete sequence of mtDNA Dloop. Mitochondrial DNA A DNA Mapp Seq Anal. 2019;30(2):273-80.

43. Lyimo CM, Weigend A, Janßen-Tapken U, Msoffe PL, Simianer H, Weigend S. Assessing the genetic diversity of five Tanzanian chicken ecotypes using molecular tools. S Afr J Anim Sci. 2013:43(4):499-510.

44. Eltanany MA, Hemeda SA. Deeper insight into maternal genetic assessments and demographic history for Egyptian indigenous chicken populations using mtDNA analysis. J Adv Res. 2016;7(5):615-23.

45. Meydan H, Jang CP, Yıldız MA, Weigend S. Maternal origin of Turkish and Iranian native chickens inferred from mitochondrial DNA D-loop sequences. Asian Australas J Anim Sci. 2016;29(11):1547.

46. Osman SA-M, Yonezawa T, MJPs N. Origin and genetic diversity of Egyptian native chickens based on complete sequence of mitochondrial DNA D-loop region. Poult Sci. 2016;95(6):1248-56.

47. Hassaballah K, Zeuh V, Lawal RA, Hanotte O, Sembene M. Diversity and origin of indigenous village chickens (Gallus gallus) from Chad, Central Africa. Adv Biosci Biotechnol. 2015;6(09):592.

\section{Publisher's Note}

Springer Nature remains neutral with regard to jurisdictional claims in published maps and institutional affiliations.
Ready to submit your research? Choose BMC and benefit from:

- fast, convenient online submission

- thorough peer review by experienced researchers in your field

- rapid publication on acceptance

- support for research data, including large and complex data types

- gold Open Access which fosters wider collaboration and increased citations

- maximum visibility for your research: over $100 \mathrm{M}$ website views per year

At $\mathrm{BMC}$, research is always in progress.

Learn more biomedcentral.com/submissions 